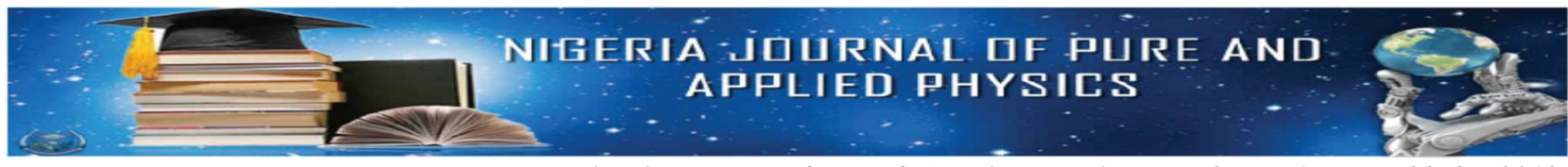

Nigeria Journal of Pure \& Applied Physics, Vol. 9, No. 1, pages 23-27, 2019

\title{
Determination of thermal properties of some ceiling material commonly used in Ijebu- Ode, Nigeria
}

\author{
J. O. Adepitan ${ }^{1}$, F. O. Ogunsanwo ${ }^{1,}$, J. D. Ayanda ${ }^{1}$, A. A. Okusanya ${ }^{1}$, A. D. Adelaja ${ }^{1}$, O. O. Oni ${ }^{1}$, \\ O. O. Odumosu ${ }^{2}$ \\ ${ }^{1}$ Department of Physics, Tai Solarin University of Education, Ijebu Ode, Nigeria. \\ ${ }^{2}$ Department of Chemical Science, Tai Solarin University of Education, Ijebu Ode, Nigeria. \\ †Corresponding Author's Email: ogunsanwofo@tasued.edu.ng godi07@yahoo.com
}

\begin{abstract}
The study investigates the thermal properties of different insulating material used in building construction in Ijebu Ode, a tropical rainforest region, south western, Nigeria. Five insulating material; asbestos, Plaster of Paris (P.O.P), PolyVinyl Chloride (PVC), hardboard and paperboard, were subjected to thermal investigation using Lee's disc electrical method. The result obtained showed that the thermal conductivities obtained are within the range of values specified for good insulating materials. Asbestos was found to be associated with the least thermal conductivity of the value $\mathbf{0 . 1 7 1 7} \mathbf{W m}^{-1} \boldsymbol{K}^{-1}$ while PVC had the highest thermal conductivity values of 1.6499 $\mathrm{Wm}^{-1} \mathrm{~K}^{-1}$. This may be associated with the temperature and the heat flux on the surface of the material. The results obtained for thermal conductivity, thermal resistivity and thermal diffusivity correlated favourably when compared with those of previous work from other locations. Asbestos being the material with the lowest thermal conductivity is therefore recommended for use as the suitable insulating ceiling material in the study area.
\end{abstract}

Keywords: thermal conductivity, diffusivity, resistivity, Lee's disc

\section{INTRODUCTION}

In heat transfer analysis, the parameters such as density, specific heat capacity, porosity, permeability and thermal conductivity of the material under investigation is of major importance. Thermal insulation is an important technology to reduce energy consumption in buildings by preventing heat gain/loss through the building envelope. Thermal properties depend solely on the temperature gradient which must occur for heat to be transferred. Several authors have used different method to determine the thermal properties of materials [1-6]. The thermal resistivity (insulating capability) of a material is measured as the inverse of thermal conductivity. Low thermal conductivity is equivalent to high insulating capability [7].

Thermal insulation is the reduction of heat transfer between objects in thermal contact or in range of radiative influence. Heat flow is an inevitable consequence of contact between objects of different temperature. Thermal insulation provides a region of insulation in which thermal conduction is reduced or thermal radiation is reflected rather than absorbed by the lower-temperature body [8]. The act of insulation is accomplished by encasing an object with material of low thermal conductivity in high thickness. Decreasing the exposed surface area could also lower heat transfer, but this quantity is usually fixed by the geometry of the object to be insulated. Many forms of thermal insulation also reduce noise and vibration, both coming from the outside and from other rooms inside a building, thus producing a more comfortable environment.

The interest of this study is borne of the fact that the climatic comfortability of the people lie solely on the use of suitable insulating material in their respective home and place of work. The use of thermal insulating material will reduce the penetration of heat into the building, therefore reducing the demand on air-conditioning. This therefore prompts the call for investigating the thermal properties of insulating materials for its suitability and usage in construction.

\section{MATERIALS AND METHODS}

\subsection{Materials}

Lee disc apparatus, three (3) mercury in glass thermometer, glycerine, multimeter, specimen samples such as Plaster of Paris (P.O.P) also known as gypsum plaster board, asbestos, PolyVinyl Chloride (PVC), hard board, paper board, D.C voltage regulator, vernier caliper, micrometer screw gauge and stop watch.

\subsection{Method}

The insulating material which was collected from different location across Ijebu Ode metropolis were processed to form thin disc of the same diameter as that of the copper disc in the Lee disc apparatus. The samples diameter and thickness were measured with a vernier caliper and micrometer screw gauge respectively. 


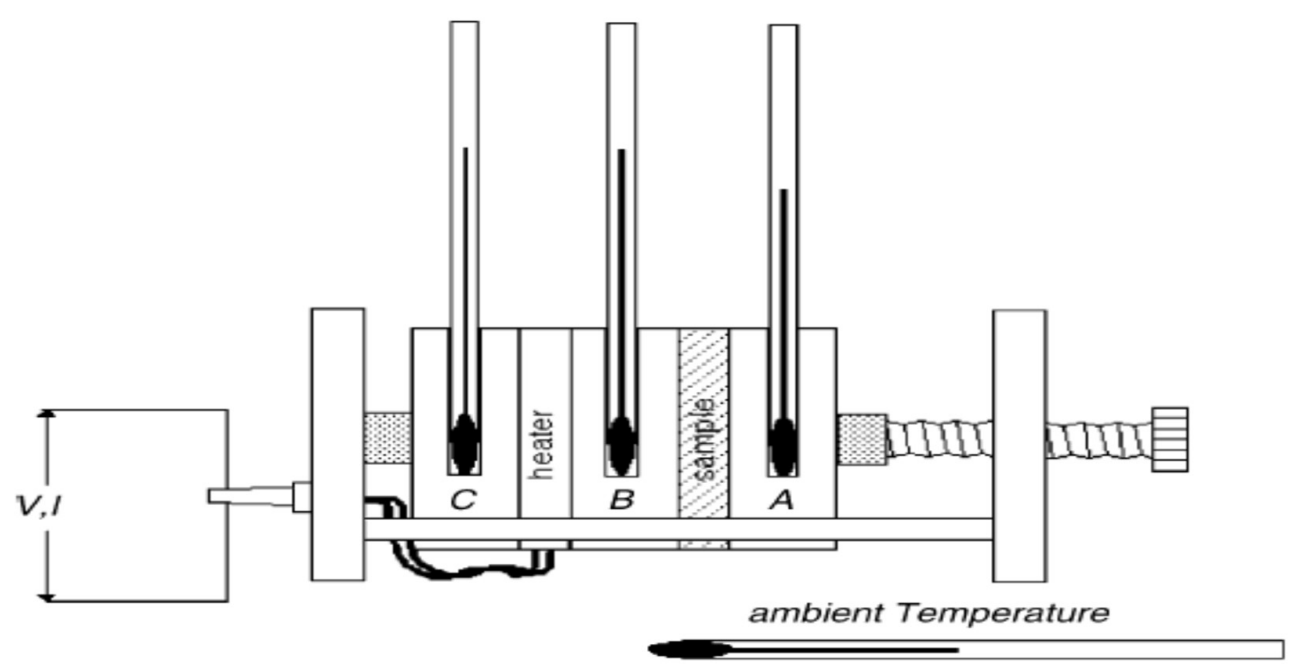

Fig. 1. Lee's disc schematic apparatus set up [9].

The equipment used for this work employed electrical heating without the need for cooling measurements, unlike that of Lee-Charlton's method which utilize a steam chest to provide a temperature of $100^{\circ} \mathrm{C}$ on one side of the sample and subsequently cooling measurements in order to calculate the heat flow through the sample. This consists of three copper plates $(\mathrm{A}-\mathrm{C})$ drilled to accept liquid-in-glass thermometers and a $6 \mathrm{~W}$ electrical plate heater of the same diameter as the copper plates. The sample to be studied was cut to the same diameter as the copper plates $(4.2 \mathrm{~mm})$. The specimen was then placed between copper plates A and B. The heater was sandwiched between plates B and C and, after tightening the clamp screw to hold all the disks together, the power to the heater was switched on. The whole assembly was placed in an enclosure to minimize the effects of draughts and a fourth thermometer was placed within the enclosure, fairly close to the apparatus, to measure the ambient temperature. At the beginning of each determination, the power from a stabilized dc supply was turned on until the average temperature of the sample (i.e. the mean of the temperature of plates $\mathrm{A}$ and $\mathrm{B}$ ) reached the desired value. The power was then adjusted to allow the temperatures of the plates to stabilize. As equilibrium was reached, in addition to the four temperature readings, the current and voltage applied to the heater was monitored. When the temperature of all parts of the apparatus had been stable to within $0.1^{\circ} \mathrm{C}$ for $30 \mathrm{~min}$, a value for the thermal conductivity of the specimen $(\mathrm{k})$ of thickness $\mathrm{d}$ and radius $\mathrm{r}$ was calculated using Eq. (1).

\section{THEORETICAL BACKGROUND} 3.1 Thermal Conductivity

Thermal conductivity is defined as the property of a material's ability to conduct heat as a result of temperature difference under steady state boundary condition. It appears primarily in Fourier's Law for heat conduction [10]. Thermal conductivity, referred to as a transport property, provides an indication of the rate at which energy is transferred by the diffusion process.

In any heat transfer study, the boundary conditions of material under investigation are of importance. This thermal boundary condition may be associated with the temperature and the heat flux on the surface of the material [11].

The thermal conductivity of an insulating material according to [9] is given in eq. (1) as

$$
k=\frac{\lambda d}{2 \pi r^{2}\left(T_{B}-T_{A}\right)}\left[a_{S}\left(\frac{T_{A}+T_{B}}{2}\right) \rightleftarrows \rightleftarrows \rightleftarrows+2 a_{A} T_{A}\right]
$$

in $J s^{-1} m^{-1}{ }^{0} C^{-1}$ or $\left(W m^{-1} K^{-1}\right)$, where $\lambda$ is joules of energy emitted from each exposed unit area of the surface measured in $m^{2} s^{-1}{ }^{0} \mathrm{C}$ above ambient temperature, $\mathrm{r}$ is radius and $\mathrm{d}$ is thickness of the sample; $a_{A}$ and $a_{S}$ are the exposed surface area (in $\mathrm{m}^{2}$ ) of disc $\mathrm{A}$ and sample $\mathrm{S}$ respectively; $k$ the thermal conductivity of the specimen; $T_{A}$ and $T_{B}$ are the temperature of disc $\mathrm{A}$ and $\mathrm{B}$ at the steady state above the ambient temperature.

\subsection{Thermal Resistivity}

The thermal resistivity, $\mathrm{R}$, is the reciprocal or inverse of thermal conductivity. It is express in eq. 2 as 


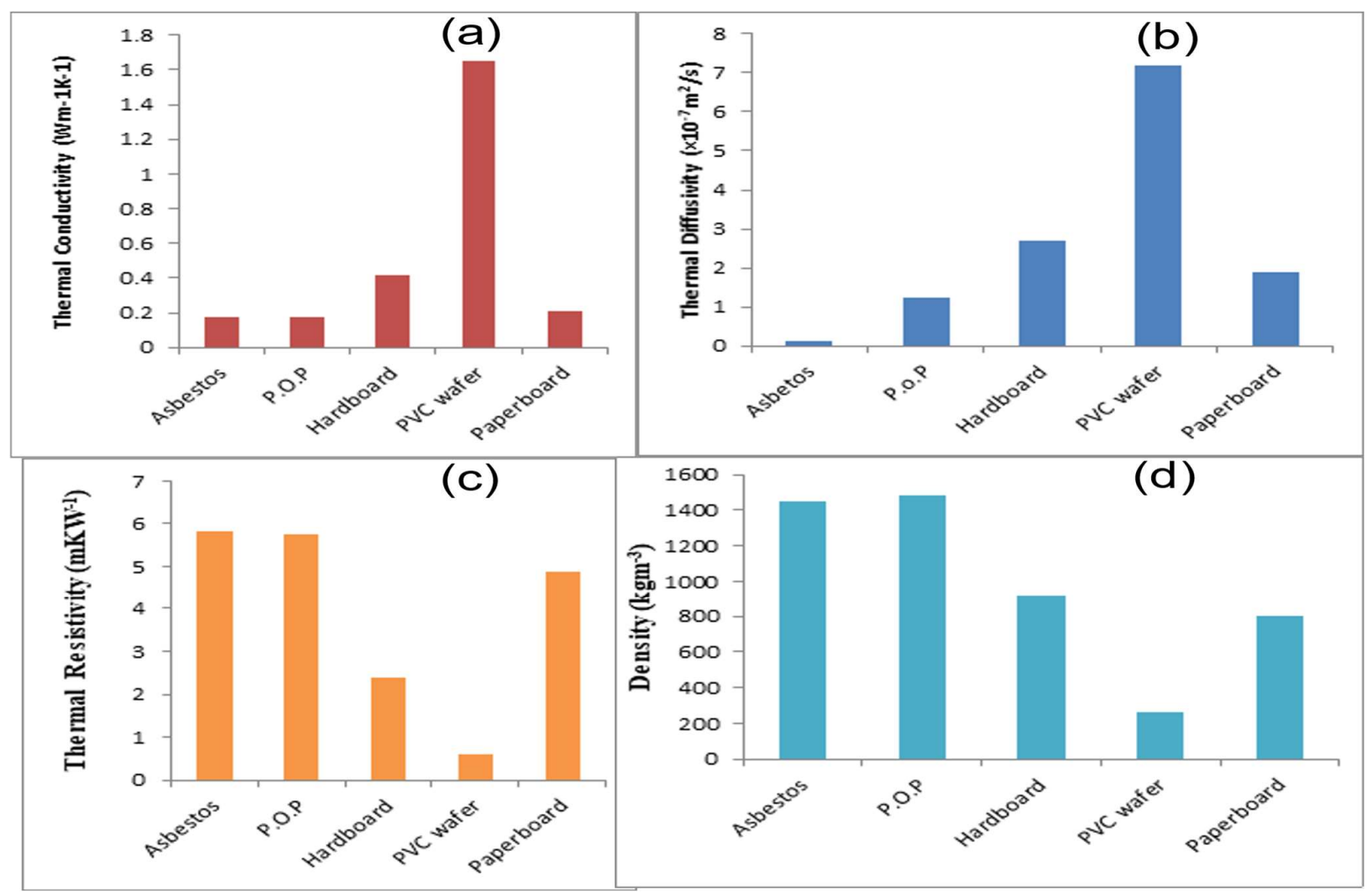

Fig. 2. Thermal properties (a) Conductivity (b) Diffusivity (c) Resistivity (d) Density of the insulating materials

$$
R=\frac{1}{k} \text { in }\left(m K W^{-1}\right)
$$

$k$ represents the thermal conductivity in $\left(W m^{-1} K^{-1}\right)$

\subsection{Thermal Diffusivity}

Thermal diffusivity is another important property of insulating materials. This is used to estimate how fast heat diffuses through a material. It is usually represented as the ratio of quantity of heat produced to the quantity of heat stored in a material. Thermal diffusivity is also a function of thermal conductivity $(k)$ which is express in eq. 3 as

$$
\alpha=\frac{k}{\rho c}
$$

where $\rho$ is the density of the material in $\mathrm{kgm}^{-3}, c$ is the specific heat capacity of the material in $\mathrm{kJ} \mathrm{kg}^{-1} \mathrm{~K}^{-1}, \alpha$ is the thermal diffusivity in $\mathrm{m}^{2} / \mathrm{s}$

\section{RESULTS AND DISCUSSION}

The thermal properties of insulating material are intrinsic in nature. The accuracy of any numerical heat transfers analysis depends majorly on the input material of the thermal properties. From the result obtained for the five insulating material, asbestos was observed to have the least thermal conductivity while the highest was associated with PVC (fig. 2a). This was also observed for thermal diffusivity (fig. 2b). The result obtained for the thermal resistivity (fig.2c) shown similar trend with that of the density of the insulating material used. This is expected because any material with high density has a very strong ability to resist the amount of heat penetrating through it, therefore resulting into low conductivity. Any material with high value of conductivity must definitely have low resistivity and vice versa; due to the fact the conductivity is the inverse of the resistivity.

Asbestos and P.O.P are the material associated with higher density and their respective resistivity values was as well obtained to be higher. These two materials being a carbonated material are chemically bound with very low affinity to heat exchange and transfer. The lowest thermal resistivity and least density value were attributed to PVC (Figure $2(\mathrm{~d})$ ). PVC being a plastic material (thermoplastic) may probably behave in the same manner as metallic material. If the heat should pass through it, there is tendency for infinitesimal expansion and which later contract therefore increasing the level of thermal conductivity.

A material with high thermal conductivity or low heat capacity will obviously have a large thermal diffusivity. The larger the diffusivity, the faster the propagation of heat into the medium. A small value of thermal diffusivity 
Table 1: Show the computed thermal properties of the insulating materials

\begin{tabular}{lllll}
\hline & Material & $\begin{array}{c}\text { Thermal Conductivity } k \\
\left(\mathrm{Wm}^{-1} \mathrm{~K}^{-1}\right)\end{array}$ & $\begin{array}{c}\text { Thermal Resistivity } R \\
\left(\mathrm{~m} K W^{-1}\right)\end{array}$ & $\begin{array}{c}\text { Thermal Diffusivity } \alpha \\
\left(\times 10^{-7} \mathrm{~m}^{2} / \mathrm{s}\right)\end{array}$ \\
\hline $\mathbf{1 .}$ & Asbestos & 0.1717 & 5.8244 & 0.1352 \\
2. & P.O.P & 0.1733 & 5.7709 & 1.2332 \\
3. & Hardboard & 0.4197 & 2.3828 & 2.6861 \\
4. & PVC wafer & 1.6499 & 0.6061 & 7.1883 \\
5. & Paperboard & 0.2047 & 4.8852 & 1.9083 \\
\hline
\end{tabular}

means that heat is mostly absorbed by the material and a small amount of heat is conducted further. [12] reported in their work that the higher density of the material, the lower the thermal conductivity and the slower the temperature propagation (thermal diffusivity) becomes.

Polyvinyl Chloride, also referred to as $P V C$, is a thermoplastic material. It is very versatile and is a widely known and used compound. Heat is conventionally found to diffuse from higher region to lower region which therefore tend to increase the thermal conductivity of any material which have similar behavior to metal such as $P V C$. $P V C$ is found to have double layer with vacuum inbetween, this may increase the diffusivity of heat produced. Although, the rate at which heat diffuses through the first layer may be high but might have been reduce (cooled off) on entering into the vacuum before reaching the second layer. Being the lightest, highest diffusivity may be experienced. With the result obtained in Figure 2 ( $a$ and b), $P V C$ absorbed more heat compared to other insulating material in the order of: Asbestos > P.O.P > Paperboard $>$ Hardboard $>$ PVC. PVC that hardens after polymerisation is not suitable for insulating and protecting wires and cables

An important function of P.O.P in a construction is to provide fire resistance by delaying temperature rises in the construction. When exposed to fire attack, the free water and the chemically bound water in gypsum plasterboard are gradually driven off at temperatures above $100^{\circ}$ C. P.O.P contains free water and chemically bound water, which is a key factor in providing fire resistance. The free water content in P.O.P is about $3 \%$ by weight, depending on the ambient temperature condition $[13,14,15]$. For dry gypsum, the chemically bound water is approximately $21 \%$ by weight [16]. The chemically bound water is dehydrated at high temperatures. The first dehydration reaction converts calcium sulphate dihydrate $\left(\mathrm{CaSO}_{4} \cdot 2 \mathrm{H}_{2} \mathrm{O}\right)$ into calcium sulphate hemihydrates $\left(\mathrm{CaSO}_{4} .1 / 2 \mathrm{H}_{2} \mathrm{O}\right)$, also known as 'Plaster of Paris'. Hence, P.O.P is hydroscopic. Due to the chemical composition such as calcium sulphate and other ingredients involve, they undergo endothermic decomposition at a particular temperature and thus delays the temperature increase in the material. By implication, P.O.P and asbestos being a carbonated materials, could be regarded as the safest ceiling material in terms of resistance to combustion in the cause of fire outbreak. This was due to the flame retardant and elemental properties inherent in the two materials.

The result obtained for the insulating material showed that in tropical region, during the day it is advisable to use either Asbestos or P.O.P as the roofing insulating material since its conductivity is found to be lower compare to the others, therefore reducing the propagation of heat into the medium. Having investigates the thermal properties, it is also necessary to consider the cost implication. Asbestos is however recommended for the lower or middle class who cannot cope with the exorbitant cost of P.O.P .

Generally, the poorer the conductivity of a material, the better its suitability as a insulating material. The value of the thermal conductivity for P.O.P in this study fall within the range $0.09-0.18 \mathrm{Wm}^{-1} \mathrm{~K}^{-1}$ [12]. It was as well suggested that if P.O.P is with larger thermal conductivity, it may simply due to large amount of calcium carbonate which possibly has a strong endothermic decomposition reaction. [17] recommended P.O.P and Asbestos as the ceiling materials that would have good thermal insulation efficiency when compared to PVC and hardboard.

The results of the thermal conductivity values obtained (Table 1) for all the insulating material investigated, falls within the limit specified by [18] for good construction and heat insulating materials which ranges from $0.023-2.9 \mathrm{Wm}^{-}$ ${ }^{1} \mathrm{~K}^{-1}$.

\section{Conclusion}

In this study, thermal properties of insulating material were investigated using the Lee's disc method. The result obtained revealed that asbesbos and P.O.P are the suitable material to be used in the tropical zone having considered the conductivity, diffusivity and resistivity as the major factor for any building engineer. The best thermal insulators have the lowest thermal conductivity; this is the property of a material that measures how well it can conduct heat through its mass. The lower the conductivity measure, the less well a material is able to conduct heat, thus enabling it to trap heat or protect contents from outside heat. However, from the economic point of view, it is 
commendable to choose an insulating material with a lower thermal conductivity and more affordability to average number of inhabitants when considering housing construction in a densely populated area.

\section{REFERENCES}

[1.] Brennan, W.P. Miller, B., and Whitwell, J.C. (1968). Thermal resitance factor in differential scanning calorimetry. J. Appl. Polym. Sci., 21: 441-453

[2.] Chiu, J. and Fair, P.G (1979) Determination of thermal conductivity by differential scanning calorimetry, Thermochim. Acta, 34: 267-273

[3.] Khanna, Y.P. Taylor,Y.P., and Chomyn, G. (1988) A new differential scanning calorimetry based approach for the estimation of thermal conductivity of polymer solids and melts Polym. Eng. Sci., 28: 10341041.

[4.] Hakvoort, G. and van Reijen, L.L. (1985). Measurement of the thermal conductivity of solid

substances by DSC, Thermochim. Acta, 93: 317-320.

[5.] Flynn, J.H.and Levin, D.M. (1988) A method for the determination of thermal conductivity of sheet materials by differential scanning calorimetry (DSC), Thermochim. Acta, 126: 93- 100.

[6.] Marcus, S.M and Blaine, R.L. (1994) Thermalconductivity of polymers, glasses and ceramics by modulated DSC. Thermochim. Acta, 243 (2): 231-239.

[7.] Bergman, T.L Lavine, A.S, Incropera, F.P and DeWitt D.P (2011). Introduction to heat transfer.

Sixth edition, John Wiley and Sons, Pp.1041

[8.] Incropera, F.P and DeWitt D.P (1990) Fundamental of heat and mass transfer. Third edition, John Wiley and Sons, Pp.2131.

[9.] Price, D.M, and Jarratt, M (2002). Thermal conductivity of PTFE and PTFE composites, Thermochimica Acta, 392-393: 231-236
[10.] Halliday D., Resnick R. and Walker J. (1997). Fundamentals of Physics (5th ed.); John Wiley and Sons, INC., NY ISBN 0-471-10558-9.

[11.] Ang, C.N., Wang Y.C. (2009). Effect of moisture transfer on specific heat of gypsum plasterboard at high temperatures. Construction and Building Materials, 23: 675-686

[12.] Wakili K.G and Hugi, E (2009). Four types of gypsum plaster boards and their thermophysical

properties under fire condition. Journal of fire sciences, 27 : $27-43$

[13.] Thomas, G. (2002). Thermal Properties of Gypsum Plasterboard at High Temperatures, Fire and Materials, 26(1): 37-45.

[14.] Gerlich J. T, Collier P. C. R and Buchanan A.H.(1996) Design of light steel-framed walls for fire resistance. Fire Matter, 20: 79-96.

[15.] Gerlich J. T (1995). Design of load bearing light steel frame walls for fire resistance, fire engineering research report 95/3. School of Engineering. New Zealand: University of Canterbury.

[16.] Mehaffey, J.R., Cuerrier, P. and Carisse, G. (1994). A Model for Predicting Heat Transfer through Gypsum Board/ Wood-Stud Walls Exposed to Fire, Fire and Materials, 18(5): 297-305.

[17.] George, N. J.,Obianwu,V. I., Akpabio, G. T. and. Obot, I. B (2010). Comparison of thermal insulation efficiency of some selected materials used as ceiling in building design, 2(3): 253-259.

[18.] Ettah, E.B, Egbe, J.G, Takim, S.A, Akpan, U.P and Oyom ,E.B (2016). Investigation of the thermal conductivity of Polyvinyl Chloride (PVC) ceiling material produced in Epz Calabar, for application tropical climate zones, IOSR Journal of Polymer and Textile Engineering, $3(2): 34-38$ 